\title{
Digital Fabrication in Promoting Student Engagement and Motivation in University Courses
}

\author{
Teemu Tokola \\ University of Oulu \\ teemu.tokola@oulu.fi
}

\author{
Niklas Saari \\ University of Oulu \\ niklas.saari@oulu.fi
}

\author{
Juha Kälkäinen \\ University of Oulu \\ juha.kalkainen@oulu.fi
}

\author{
Juha Röning \\ University of Oulu \\ juha.roning@oulu.fi
}

\begin{abstract}
Project work represents a significant part of university studies, making them an important concern for teaching development. Many universities have used international engineering competitions such as the Eurobot robotics competition as a tool in engaging and motivating students. Based on a theory on why these competitions are successful, we propose how smaller-scale projects can use digital fabrication and joint projects to reach similar results. We present a case study of an ongoing robotics project course in the field of computer engineering, showing how a practical implementation of these ideas and how the field-specific problem of software intercommunication and interoperability can be solved using the Robotic Operating System software framework. While the course is still in progress, initial observations indicate that the course is going to be successful.
\end{abstract}

\section{CCS CONCEPTS}

-Applied computing Collaborative learning • Computer systems organization Robotics $\quad$ C Computer systems organization $\sim$ Embedded hardware - Computer systems organization $\sim$ Embedded software

\section{KEYWORDS}

3D printing; student retention; robotics and education; ROS

\section{ACM Reference format:}

Teemu Tokola, Niklas Saari, Juha Kälkäinen and Juha Röning. 2019. Digital Fabrication in Promoting Student Engagement and Motivation in University Courses. In Proceedings of FabLearn Europe 2019 conference. 2 pages.

https://doi.org/10.1145/3335055.3335059
Permission to make digital or hard copies of part or all of this work for personal or classroom use is granted without fee provided that copies are not made or distributed for profit or commercial advantage and that copies bear this notice and the full citation on the first page. Copyrights for third-party components of this work must be honored. For all other uses, contact the Owner/Author.

FabLearn Europe '19, May 28-29, 2019, Oulu, Finland

(C) 2019 Copyright is held by the owner/author(s).

ACM ISBN 978-1-4503-6266-5/19/05.

https://doi.org/10.1145/3335055.3335059

\section{Introduction}

Large student projects represent a significant investment both for academic organisations and students. With between 150 - 300 hours of work, projects form a major part of the student's professional development, making improving the arrangements of project courses crucial. Many universities have used large engineering events such as formula competitions [1,2] for mechanical engineering and related fields and various robotics competitions $[3,4,5]$ in the computer engineering field to provide challenge, sought-after skills and learning experiences to students. At the same time, these projects require significant time, funding, project management and a clear focus on the topic dictated by the competition. As individual teachers might not have the necessary resources, the topics might not be a good fit to the aims of the student program in question or the time spent by students on that particular area should be smaller. Such events cannot answer all project needs. However, understanding why these projects are efficient in fostering student engagement and motivation could allow teachers to reap those benefits without the downsides.

\section{Theoretical Background and course design}

We propose that the success of large engineering competitions comes from the existence of a self-designed real-world artifact and the real-world problems it must solve. Additionally, students are responsible for the whole project team, making weak project outcomes reflect bad on them in the eyes of their peers, and publicly attempting to pass a sub-par product would not satisfy engineeringminded students themselves either.

The design of the case study course started from analysis of motivation theories and how these could explain how the success of engineering competitions could be used in smaller scale projects. Of the well-known theories of motivation, Herzberg's theory $[6,7]$ of hygiene and motivation factors seemed to be best suited for both answering this question and providing clear guidelines for course project topic formulation. Additionally, we feel the concept of equity from Adams [8] should be incorporated as a hygiene factor. Additionally, we feel that theories suitable to engineering course planning are presented by Hackman and Oldman [9] (psychological states related to motivation), McGregor[10] (theories X and Y) and Ouchi [11] (theory Z).

In Herzberg's theory the absence of hygiene factors (such as administration, supervision, relationships, working conditions, 


\section{Figure 1: The project product concept}

salary, status, security and equity) causes demotivation and conversely the existence of motivational factors (such as achievement, recognition, work itself, responsibility, advancement and growth) foster motivation. Large engineering competitions are unbeatable in many of the hygiene factors are well taken care of and smaller course projects cannot compete with conditions and status, but these are secondary to the motivational factors, in which course project can compete, as long as these factors are taken care of in planning. While in large competitions motivational factors are self-evident through the grandeur surrounding a large international event, in course projects the factors need to be communicated by the teacher and shown through a good choice of topic that allows these motivation factors to evident, may allow teacher to reap many of the motivational benefits of engineering competitions.

We propose that digital fabrication and collaborative projects could be used to improve student engagement and motivation by promoting a feeling of responsibility for and a sense of belonging to a joint project. A concrete, digitally fabricated artifact, compelling narrative and a critical responsibility for a key feature of the project outcome allow students to engage with the project earlier and with more dedication than a more abstract project, in which the apparent stakeholders are just the group members.

\section{Case study: 2019 Project course}

We present a case study for a project course arranged in Spring 2019 in the (INSTITUTION REDACTED), with the theme of a chess-playing robot as shown in Figure 1. First prototype of a robotic arm of the complete system was constructed for the beginning of the course. This allowed the students to see a part of the artifact right at the beginning of the course for motivation and imparting a feeling of concreteness. 17 students were divided into 6 groups and each chose subtasks consisting either of only software

\section{Figure 2: CAD models of robot arm and neck}

or both software and fabricated components to be developed in the local FabLab (see Figure 2 for example models). These topics, ranging from machine vision and AI to improving and designing new parts to the robot, are needed for the final product to work as intended, and the Robotic Operating System ROS [12] was used to ensure software compatibility between student projects.

In previous years the course had similar project themes, but without digital fabrication and without group projects linked to a joint project. While the number of students is insufficient to make strong conclusions, and comparing projects and students from different years introduces additional variables that make any conclusions indicative at best, the case study aims to determine if the described project improves the pass rate and project duration and how the student engagement as measured in total hours spent on the project changes from previous years. With a month to go until the end of the course, it seems that in all these measures the course is going to be more successful than previous iterations, and that the overall system developed will be functional. Achieving this principal aim seems to be a important source of motivation for students in the last part of the course.

\section{Conclusions}

By carefully selecting suitable topics and arrangements with consideration to underlying sources of motivation, the same mechanisms that make engineering competitions engaging and motivating for students can also be used in smaller scale engineering project courses. The authors have used this approach in an ongoing project course with preliminary but encouraging results to improve engagement and lower the number of groups abandoning the project course.

\section{ACKNOWLEDGMENTS}

Redacted. 
Digital Fabrication in Promoting Student Engagement and Motivation in University Courses

\section{REFERENCES}

[1] Davies HC. Formula student as part of a mechanical engineering curriculum. European Journal of Engineering Education 2013; 38: 485-496.

[2] SAE International. Formula SAE. https://www.fsaeonline.com/, 2019 Accessed:2019-03-05

[3] Schneider, F. E. The european land robot trial. https://www.elrob.org/, 2019 Accessed:2019-03-05.

[4] EUROBOT. Eurobot - international student robotic contest http://www.eurobot.org/, 2019. Accessed: 2019-03-05.12.

[5] euRobotics. The european robotics league. https://eurobotics.net/robotics_league/, 2019. Accessed: 2019-03-05.

[6] Herzberg, F., M. B. . S. B. B.The Motivation to Work(2nd ed.). New York: John Wiley \& Sons, 1959.

[7] Gawel, J. E. Herzberg's theory of motivation and Maslow's hierarchy of needs. Practical Assessment, Research \& Evaluation, 5, 11 (1997), 3.

[8] Adams, J. S. Inequity in social exchange. In Berkowitz, L. ed. Advances in experimental social psychology. New York: Academic Press, 1965.

[9] Hackman, J. R. and Oldham, G. R. Motivation through the design of work: test of a theory. Organ. Behav. Hum. Perform., 16, 2 (1976), 250 DOI=//doi.org/10.1016/0030-5073(76)90016-7".

[10] McGregor D. The human side of enterprise. New York: McGraw-Hill, 1960.

[11] Ouchi, W. Theory z: How american business can meet the Japanese challenge Business Horizons 24, 6 (1981),82-83.

[12] Joseph, L.ROS Robotics Projects. Packt Publishing, 2017 